\title{
Effect of long-term L-thyroxine treatment on bone mineral density in young adults with congenital hypothyroidism
}

\author{
Mariacarolina Salerno, Teresa Lettiero, Antonella Esposito-del Puente ${ }^{1}$, Valentina Esposito, Donatella Capalbo, \\ Assunta Carpinelli ${ }^{2}$, Stefania Padula ${ }^{2}$ and Antonio del Puente ${ }^{2}$ \\ Department of Pediatrics, University Federico II, ${ }^{1}$ Department of Pediatrics, S.Maria della Pietà Hospital, and ${ }^{2}$ Rheumatology Unit, University Federico II, \\ Naples, Italy \\ (Correspondence should be addressed to M Salerno, Department of Pediatrics, University Federico II, via S. Pansini, 580131 Napoli, Italy; \\ Email: salerno@unina.it)
}

\begin{abstract}
Objective: To evaluate whether long-term L-thyroxine therapy in young adults with congenital hypothyroidism may affect bone mineral density (BMD).

Design: Thirty-seven subjects with congenital hypothyroidism, detected by neonatal screening and longitudinally followed from the time of diagnosis and treatment (26 \pm 4 days) up to the age of $17.8 \pm 1.0$ years, were studied.

Methods: Spinal (L2-L4) BMD, measured by dual-energy X-ray densitometry, and bone quality, measured as amplitude-dependent speed of sound (Ad-SoS) by quantitative ultrasound, were evaluated.

Results: Z-score mean values ( \pm S.D.) of BMD $(-0.3 \pm 0.7)$ and Ad-SoS $(-0.7 \pm 1$. 1$)$ were slightly below the average but within the normal range. Ad-SoS resulted in a z-score below -1 in $38 \%$ of patients as compared with BMD which resulted in a z-score below -1 in only $13.5 \%$ of subject. No significant differences were observed between males (BMD, $-0.3 \pm 0.7$; Ad-SoS, $-0.9 \pm 1.0$ ) and females (BMD, $-0.3 \pm 0.7$; Ad-SoS, $-0.5 \pm 1.2$ ) or when dividing patients on the basis of aetiological defects; ectopic gland (BMD, $-0.3 \pm 0.6$; Ad-SoS, $-0.8 \pm 0.9$ ), athyreosis (BMD, $-0.3 \pm 0.9$; Ad-SoS, $-0.8 \pm 1.0$ ) and eutopic gland (BMD, $-0.3 \pm 0.8$; Ad-SoS, $-0.4 \pm 1.3$ ). No significant relationships were observed between BMD or Ad-SoS z-score and hormonal status or L-thyroxine dosages at the time of the study or during the pubertal period.

Conclusions: The careful monitoring of serum thyroid-stimulating hormone and adjustment of L-thyroxine dosage avoided the significant deleterious effects of prolonged L-thyroxine replacement therapy on bone tissue in adolescents and young adults with congenital hypothyroidism treated from the neonatal period.
\end{abstract}

European Journal of Endocrinology 151 689-694

\section{Introduction}

Osteoporosis is one of the major health problems in adults (1); however, this condition has recently become a pediatric concern, too. In fact, the most important factor in the prevention of osteoporosis is the attainment of an optimal peak bone mass, which is mainly reached during late adolescence or early adulthood (2). In healthy subjects, bone mass increases through childhood, with maximal bone mass accrual occurring in early to mid puberty and continuing, at a lower rate, in late puberty $(2-4)$; thus osteoporosis prevention should begin at this age. The attainment of peak bone mass is the result of interaction of several factors such as genetic, ethnic, hormonal and nutritional factors, lifestyle and physical activity $(5,6)$. Any factors adversely impacting on bone acquisition during childhood and adolescence can potentially have long-lasting detrimental effects on bone tissue, predisposing it to osteoporosis. Therefore, young people affected by chronic pathologies, which are potentially harmful for the bone, should be screened for bone disturbance. Thyroid disease is one of the most common endocrine disorders in both childhood and adulthood. In adults with thyroid cancer, goiters or thyroid nodules, treatment with high doses of L-thyroxine (L-T4), aimed at suppressing serum thyroid-stimulating hormone (TSH) levels, leads to prolonged subclinical hyperthyroidism, which has been associated with reduced bone mass and premature development of osteoporosis (7). Thyroid hormones directly affect bone cells stimulating osteoclastic and osteoblastic activity, with a predominance of bone resorption during hyperthyroidism, resulting in a decreased bone mass $(8,9)$. A significant reduction of peripheral bone mineral density (BMD) has been found in children and adolescents receiving L-T4 overtreatment for goiter, Hashimoto's thyroiditis or thyroid cancer (10), however 
other studies indicated that long-term L-T4 treatment does not seem to affect bone mineral metabolism and BMD in patients with thyroid diseases $(11-14)$. Congenital hypothyroidism $(\mathrm{CH})$ is one of the most common thyroid diseases in children; early detection by neonatal screening has significantly improved mental and auxological outcomes. A few data on bone mineral metabolism in children with $\mathrm{CH}$ are reassuring $(11,13)$; however, there are no data on young adults with $\mathrm{CH}$ detected by neonatal screening. The aim of the present study was to evaluate whether long-term L-T4-replacement therapy in young adults with $\mathrm{CH}$, detected by neonatal screening and treated since the first weeks of life, may affect BMD.

\section{Patients and methods}

\section{Patients}

A total of 37 Caucasian patients ( 25 females, 12 males) aged $17.8 \pm 1.0$ years (range $16.0-19.6$ years) with $\mathrm{CH}$ participated in the study. All patients had been detected by neonatal screening and followed longitudinally, from the time of diagnosis to the time of the study. Patients with other chronic diseases were excluded from the study. The diagnosis was confirmed by serum thyroid function tests. L-T4 replacement therapy started, immediately after the first evaluation, at a mean age of 26 \pm 4 days (range 12-30 days) at a mean initial dose of $6.6 \pm 0.9 \mu \mathrm{g} / \mathrm{kg}$ per day. Replacement therapy was modified during follow-up according to clinical and hormonal evaluation in order to maintain serum TSH levels in the normal range and serum free thyroxine in the upper normal range. The aetiological diagnosis of $\mathrm{CH}$ was made on the basis of technetium-99m (99m Tc)pertechnetate or iodine-123 thyroid scans at the time of diagnosis or at the age of 3 years, after the withdrawal of L-T4 therapy for 6 weeks. Cases were classified into three groups: athyreosis $(n=10)$, ectopic gland $(n=19)$ and eutopic gland $(n=8)$.

At study entry all patients underwent height and weight measurement; the degree of adiposity was expressed as body mass index (BMI; weight/height ${ }^{2}$ ). All subjects had completed their pubertal development (15), females had regular menstrual cycles (every 25-35 days) and all patients had already reached their adult height (defined as a growth of less than $1.0 \mathrm{~cm} /$ year during the preceding year). Serum calcium, phosphorus, alkaline phosphatase, parathyroid hormone (PTH), TSH and thyroid hormones were determined in the morning after a 12-h fast. All subjects had normal liver and kidney function and did not take drugs known to affect skeletal or mineral metabolism. None of them had a history of hereditary bone disease.

The total daily calcium intake was calculated by a semiquantitative food frequency questionnaire, specifically compiled to investigate the calcium consumption (16). All subjects had normal physical activity. Five patients were mild smokers (less than 10 cigarettes per day) and three were moderate drinkers (beer or wine occasionally). In order to evaluate the influence of thyroid hormone status on bone mass accrual during puberty, mean values were calculated from all serum TSH and serum free thyroxine evaluations carried out from the onset of puberty to the time of the study; the mean L-T4 dose taken in the same period of time was also calculated.

Informed consent to participate into the study was obtained from the patients' parents when the chronological age was lower than 18 years, and directly from each older subject.

\section{Bone densitometry}

The BMD was measured by dual energy X-ray absorptiometry (DXA), using an Hologic QDR 1000 densitometer (Hologic, Waltham, MA, USA) at the lumbar spine (L2-L4). Daily phantom scanning during a 1-year period yielded a coefficient of variation of $0.56 \%$. Measurements were always performed by the same operator. Individual BMD values were expressed as $\mathrm{g} / \mathrm{cm}^{2}$ and as BMD z-score, calculated on the basis of the normal reference values for age and sex provided by the DXA system manufacturer; their data in fact did not differ significantly from those obtained on a local sample in a study performed when the machine was set up (17). In order to obtain more complete information on bone tissue, young adults with $\mathrm{CH}$ were also investigated by quantitative ultrasound (QUS) measurements using a DBM Sonic 1200R bone profiler (Igea S.r.l., Carpi, MO, Italy). The sound frequency employed was $1.25 \mathrm{MHz}$, and the amplitude-dependent speed of sound (Ad-SoS) was determined. QUS was performed on the second to the fifth proximal phalanges of the non-dominant hand and the mean value per person was calculated. Measurements were always performed by the same operator and the coefficient of variation was $0.73 \%$, determined by repeated measurements in a subgroup of 12 subjects (three measurements per person on three different days). Ad-SoS results were expressed as z-scores calculated on the basis of the normal values for age and sex obtained in a large Italian population sample (18). Among adults both BMD and Ad-SoS z-score can be considered within the normal range when above -1 SDS, while different values identify osteopenic or osteoporotic patients (19). At present no consensus exists in pediatric patients, but it seems reasonable to consider the same consecutive cut-off ( -1 SDS) at least for normality definition, especially as we are dealing with a study population of young adults.

\section{Statistical analysis}

To give greater power to the statistical analysis, we used as a control group the large reference population 
samples mentioned previously (18). The sample size was calculated assuming the conventional value of $\alpha=0.05$ and a value of $\beta=0.2$. The expected difference for the variables of interest (BMD and Ad-SoS) was $10 \%$. Considering an S.D. value of up to $10 \%$ for such variables, the number of cases needed was estimated to be at least 16 .

Data are reported as means \pm S.D. The statistical analysis was performed using the Student's $t$-test for unpaired data and the Mann-Whitney rank-sum test as appropriate. Regression coefficients were computed by multiple regression analysis. Statistical significance was indicated by $P<0.05$.

\section{Results}

Clinical, biochemical and hormonal findings as well as BMD and QUS results of $\mathrm{CH}$ patients are reported in Table 1. Z-score mean values for BMD $(-0.3 \pm 0.7$ SDS) and Ad-SoS $(-0.7 \pm 1.1$ SDS) resulted within the normal range, even though the analysis of $95 \%$ confidence intervals (CI) indicates that z-score mean values are slightly but significantly different (95\% CI not inclusive of zero) from the reference mean value for both BMD (CI, - 0.53 to - 0.06) and Ad-SoS (CI, -1.1 to -0.35$)$. In the majority of patients $(86.5 \%)$ BMD resulted in a $z$-score of between +2 and -1 ; in only five subjects (13.5\%) and was BMD below a zscore of -1 . Ad-SoS showed a z-score between +2 and -1 in $62 \%$, but 14 out 37 patients (38\%) showed z-score values below -1 .

No significant differences were observed between males (BMD, $-0.3 \pm 0.7$ SDS; Ad-SoS, 0.9 \pm 1.0 SDS) and females (BMD, $-0.3 \pm 0.7$ SDS; Ad-SoS, $-0.5 \pm 1.2$ SDS) as shown in Table 1 , or dividing patients on the basis of aetiological defect; ectopic gland (BMD, - 0.3 \pm 0.6 SDS; Ad-SoS, $-0.8 \pm 0.9$ SDS), athyreosis (BMD, $-0.3 \pm 0.9$ SDS; Ad-SoS, $-0.8 \pm 1.0$ SDS) and eutopic gland (BMD, $-0.3 \pm 0.8$ SDS; AdSoS, $-0.4 \pm 1.3$ SDS) (Fig. 1).

Daily calcium intake was below the recommended intake of $1300 \mathrm{mg} /$ day (5) in the majority of patients. Results from the food frequency questionnaire showed that the mean calcium consumption in our patients was $829 \pm 354 \mathrm{mg} /$ day (range $317-2037 \mathrm{mg} /$ day). In 18 subjects $(48.6 \%)$ with a calcium intake of below $800 \mathrm{mg} /$ day (mean \pm S.D., $571 \pm 137 \mathrm{mg} /$ day), BMD z-score $(-0.4 \pm 0.8$ SDS $)$ and Ad-SoS z-score $(-0.8 \pm 1.1$ SDS $)$ were not different from patients with higher $(1073 \pm 323 \mathrm{mg} /$ day) calcium consumption (BMD z-score, -0.2 \pm 0.6 SDS; Ad-SoS z-score, $-0.7 \pm 1.2$ SDS)

Four females, with familial delay of puberty, who experienced menarche at a mean age of $15.1 \pm 0.9$ years, showed a significant reduction in BMD zscore $(-1.3 \pm 0.7$ SDS $)$ as compared with females who had menarche at a mean age of $12.1 \pm 0.9$ years (BMD z-score, $-0.1 \pm 0.5$ SDS; $P<0.0007$ ); Ad-SoS z-score was also lower in females with delayed menarche $(-1.5 \pm 1.1$ versus $0.8 \pm 1.0$ SDS $)$; however, the difference was not statistically significant. Moreover, no significant differences were observed between the two groups with regard to serum TSH, serum thyroid hormones or L-T4 replacement therapy either at the time of the study or during the pubertal period; however, a trend towards repeatedly higher serum TSH values was observed in girls with delayed puberty, as showed in Table 2 . Using multiple regression analysis, no significant relationships were observed between z-scores of BMD or Ad-SOS and hormonal status or L-T4 dosages at the time of the study or during the pubertal period, controlling for confounding variables.

Table 1 Main clinical, biochemical and bone mineral data (means \pm S.D.) of subjects with $\mathrm{CH}$. Pubertal values are mean values from the onset of puberty to the time of the study.

\begin{tabular}{|c|c|c|c|}
\hline & All $(n=37)$ & Males $(n=12)$ & Females $(n=25)$ \\
\hline Age (years) & $17.8 \pm 1.0$ & $17.6 \pm 0.8$ & $17.9 \pm 1.1$ \\
\hline Height $(\mathrm{cm})$ & $166.1 \pm 8.5$ & $174.2 \pm 8.8$ & $162.2 \pm 5.0$ \\
\hline Target height $(\mathrm{cm})$ & $160.6 \pm 7.3$ & $166.5 \pm 7.4$ & $157.7 \pm 5.4$ \\
\hline Body mass index $\left(\mathrm{kg} / \mathrm{m}^{2}\right)$ & $23.0 \pm 3.3$ & $23.5 \pm 3.5$ & $23.0 \pm 3.0$ \\
\hline Serum TSH $(\mathrm{mU} / \mathrm{l})$ & $3.0 \pm 3.2$ & $3.4 \pm 2.6$ & $2.9 \pm 3.0$ \\
\hline Serum FT4 (pmol/l) & $16.8 \pm 2.7$ & $16.7 \pm 1.9$ & $17.0 \pm 3.0$ \\
\hline L-T4 ( $\mu \mathrm{g} / \mathrm{kg} /$ day) & $2.1 \pm 0.4$ & $2.0 \pm 0.4$ & $2.2 \pm 0.4$ \\
\hline Serum calcium (mM/l) & $2.5 \pm 0.1$ & $2.5 \pm 0.1$ & $2.5 \pm 0.1$ \\
\hline Serum phosphorus (mM/l) & $1.4 \pm 0.2$ & $1.3 \pm 0.2$ & $1.4 \pm 0.3$ \\
\hline Total alkaline phosphatase (U/I) & $181 \pm 73$ & $229 \pm 105$ & $160 \pm 44$ \\
\hline Serum PTH (pM/l) & $2.8 \pm 0.9$ & $3.2 \pm 1.0$ & $2.8 \pm 0.9$ \\
\hline Calcium intake (mg/day) & $829 \pm 354$ & $856 \pm 446$ & $816 \pm 311$ \\
\hline Pubertal mean serum TSH (mU/l) & $4.3 \pm 2.8$ & $3.9 \pm 1.3$ & $4.4 \pm 3.3$ \\
\hline Pubertal mean serum FT4 (pM/l) & $19.3 \pm 2.5$ & $18.9 \pm 1.7$ & $19.6 \pm 2.9$ \\
\hline Pubertal mean L-T4 ( $\mu \mathrm{g} / \mathrm{kg} /$ day) & $2.5 \pm 1.1$ & $2.2 \pm 0.7$ & $2.6 \pm 1.3$ \\
\hline BMD z-score & $-0.3 \pm 0.7$ & $-0.3 \pm 0.7$ & $-0.3 \pm 0.7$ \\
\hline Ad-SoS z-score & $-0.7 \pm 1.1$ & $-0.6 \pm 1.2$ & $-0.5 \pm 1.2$ \\
\hline
\end{tabular}




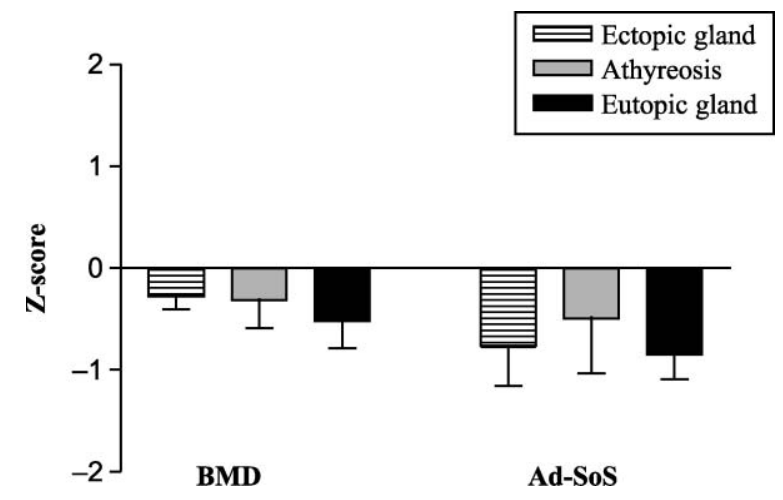

Figure 1 Z-score mean values ( \pm S.D.) of BMD and Ad-SoS in $\mathrm{CH}$ patients divided on the basis of aetiology, as shown. No significant differences were observed between ectopic gland (BMD, - 0.3 \pm 0.6 ; Ad-SoS, $-0.8 \pm 0.9 \mathrm{SDS}$ ), athyreosis (BMD, $-0.3 \pm 0.9$; Ad-SoS, $-0.8 \pm 1.0$ SDS) and eutopic gland (BMD, $-0.3 \pm 0.8 ;$ Ad-SoS, $-0.4 \pm 1.3$ SDS).

\section{Discussion}

Our results indicate that long-term L-T4 replacement therapy in adolescents and young adults with $\mathrm{CH}$, treated from the neonatal period, does not significantly affect bone mass, as evaluated by DXA and QUS. Our results confirm for adults the findings of Leger et al. (13) in children, showing that carefully monitored L-T4 therapy in $\mathrm{CH}$ patients is not detrimental to the skeleton. To the best of our knowledge this is the first study evaluating bone tissue in young adults with $\mathrm{CH}$ detected by neonatal screening.

Insufficient accumulation of skeletal mass during adolescence increases the likelihood of osteoporosis and fracture later in life (5). In order to prevent osteoporosis it is important that adolescents will adequately attain their peak bone-mass potential. Normal bone mineral accretion during childhood and adolescence is a complex process involving genetic, ethnic, nutritional, hormonal and environmental factors such as physical activity and smoking $(6,20)$.

Table 2 Hormonal and bone mineral data (means \pm S.D.) in females with $\mathrm{CH}$ divided on the basis of pubertal development. Pubertal values are mean values from the onset of puberty to the time of the study.

\begin{tabular}{lcc}
\hline & $\begin{array}{c}\text { Normal puberty } \\
(n=21)\end{array}$ & $\begin{array}{c}\text { Delayed puberty } \\
(n=4)\end{array}$ \\
\hline Serum TSH $(\mathrm{mU} / \mathrm{l})$ & $2.3 \pm 2.9$ & $5.7 \pm 4.3$ \\
Serum FT4 $(\mathrm{pM} / \mathrm{l})$ & $13.5 \pm 2.1$ & $11.4 \pm 3.1$ \\
L-T4 $(\mu \mathrm{g} / \mathrm{kg} / \mathrm{day})$ & $2.1 \pm 0.4$ & $2.2 \pm 0.2$ \\
Pubertal mean & $4.1 \pm 3.2$ & $5.7 \pm 3.9$ \\
$\quad$ serum TSH $(\mathrm{mU} / \mathrm{l})$ & $15.1 \pm 2.4$ & $15.5 \pm 1.5$ \\
Pubertal mean & & \\
$\quad$ serum FT4 $(\mathrm{pM} / \mathrm{l})$ & $2.6 \pm 1.3$ & $2.5 \pm 0.9$ \\
Pubertal mean & & \\
$\quad$ L-T4 $(\mu \mathrm{g} / \mathrm{kg} / \mathrm{day})$ & $-0.1 \pm 0.5$ & $-1.3 \pm 0.7^{*}$ \\
BMD z-score & $-0.8 \pm 1.0$ & $-1.5 \pm 1.1$ \\
Ad-SoS z-score & &
\end{tabular}

${ }^{*} P<0.0007$ versus females with normal puberty.
Hyperthyroidism is a well-described risk factor for osteoporosis (19). Some studies have suggested that adults receiving high doses of L-T4-replacement therapy may be at risk of excessive bone loss; in particular, a reduction in BMD has been reported following exogenous administration of high L-T4 doses used to fully suppress TSH in cases of thyroid cancer, goiters or nodules. Further, a review of cross-sectional and prospective studies examining the effect of thyroid hormone suppression on skeletal integrity in adults has shown neither significant negative effect nor a decrease in BMD (21). Conflicting results have also been reported in children. A significant reduction in peripheral BMD has been found in children and adolescents receiving suppressive doses of $\mathrm{L}-\mathrm{T} 4$ treatment for endemic goiter, Hashimoto's thyroiditis or thyroid cancer (10). However the majority of studies suggest that long-term L-T4 treatment in children and adolescents with $\mathrm{CH}$ (11), diffuse goiter (14) or with chronic lymphocytic thyroiditis (12) did not affect BMD nor had a negative effect on the attainment of peak bone mass. These results suggest that careful regulation of thyroid replacement is critical.

Although our patients were often treated with mean L-T4 doses higher than that recommended for young adults (22), and serum free L-T4 levels were often found in the upper limit of normal range, serum TSH values were never suppressed without any significant negative effect on BMD and QUS. Leger et al. (13) have recently shown normal BMD in children with $\mathrm{CH}$ as well as normal serum levels of calcium, phosphate, alkaline phosphatase, parathyroid hormone and 25-hydroxyvitamin D. They were unable to find any relationship between BMD and L-T4 dosage or biochemical markers of bone formation.

The importance of pubertal hormone changes on bone mineral acquisition is demonstrated by the presence of osteopenia in patients with abnormal pubertal development (6). Men with a history of constitutional delay in puberty may have decreased bone mass, although data are conflicting $(23,24)$. In females, a delay in the normal timing of pubertal development results in a reduced bone mass; in particular, in young women with a history of delayed menarche, an increased fracture rate has been reported (6). In our case a few girls who had delayed menarche showed a significantly reduced BMD. However, it has been demonstrated that in normal individuals lumbar peak bone mass may be achieved 1-2 years after the attainment of final height $(25-27)$ and that a slight gain in BMD may be observed in the 2 years following the menarche (28). Therefore, further follow-up will clarify whether the reduced BMD observed in these girls may only be related to a delay in their attainment of peak bone mass.

Calcium intake has been shown to correlate with BMD in children and adolescents. Several studies have documented that a low calcium intake may affect 
bone mineral status while an increment in bone mass and bone density is observed with dietary calcium supplement $(29,30)$. In this study we did not observe a difference in both BMD and QUS between patients with low or normal calcium intake. However this was not among the aims of the study. Of different methods of bone-mass evaluation currently in use, DXA is considered the gold standard for BMD measurement. However, ultrasound instruments using attenuation and/or velocity propagation determinations, not based on radioactive sources or ionizing radiation, have been developed for the screening of subjects at high risk of osteoporosis (31). QUS is a new and non-invasive method of evaluating bone tissue, and it is more sensitive to structural bone changes than the traditional methods because ultrasound velocity depends on bone density, architecture and elasticity (18). In our study, as in others, QUS and DXA gave similar results in the evaluation of patients with chronic pathologies potentially affecting bone metabolism (32).

In conclusion our results indicate that the careful monitoring of serum TSH and adjustment of L-T4 dosage avoided significant deleterious effects of prolonged L-T4-replacement therapy on bone tissue in patients with $\mathrm{CH}$. The finding of reduced bone density in a low percentage of patients, mainly detected by QUS, suggests that, during history-taking in an adult patient in whom skeletal health is being reviewed, L-T4 replacement in childhood may prove to be a potential adverse factor.

\section{Acknowledgements}

We thank Stefania Leopaldi for her technical assistance.

\section{References}

1 Lindsay R \& Meunier PJ. Osteoporosis: review of the evidence for prevention, diagnosis and treatment and cost-effectiveness analysis. Osteoporosis International $1998 \mathbf{8 ~ S 1 - S 8 8 . ~}$

2 Theintz G, Buchs B, Rizzoli R, Slosman D, Clavien H, Sizonenko PC \& Bonjour JP. Longitudinal monitoring of bone mass accumulation in healthy adolescent girls: evidence for marked reduction after 16 years of age at the levels of lumbar spine and femoral neck in female subjects. Journal of Clinical Endocrinology and Metabolism 199275 1060-1065.

3 Glastre C, Braillon P, David L, Cochat P, Meunier PJ \& Delmas PD. Measurement of bone mineral content of the lumbar spine by dual energy x-ray absorptiometry in normal children: correlations with growth parameters. Journal of Clinical Endocrinology and Metabolism 199070 1330-1333.

4 Rubin K, Schirduan V, Gendreau P, Sarfarazi M \& Dalsky G. Predictors of axial and peripheral bone mineral density in healthy children and adolescents, with special attention to the role of puberty. Journal of Pediatrics 1993123 863-870.

5 Cromer B \& Harel Z. Adolescents: at increased risk for osteoporosis? Clinical Pediatrics 200039 565-574.

6 Soyka LA, Fairfield WP \& Klibanski A. Hormonal determinants and disorders of peak bone mass in children. Journal of Clinical Endocrinology and Metabolism 200085 3951-3962.
7 Ross DS. Editorial: monitoring L-thyroxine therapy: lessons from the effects of L-thyroxine on bone density. American Journal of Medicine $1991911-4$.

8 Mundy GR, Shapiro J, Bandelin JG, Canalis EM \& Raisz LG. Direct stimulation of bone resorption by thyroid hormones. Journal of Clinical Investigation $1976 \mathbf{5 8} 529-534$.

9 Mosekilde L, Eriksen EF \& Charles P. Effects of thyroid hormone on bone and mineral metabolism. Endocrinology and Metabolism Clinics of North America 199019 35-63.

10 Radetti G, Castellan C, Tatò L, Platter K, Gentili L \& Adami S. Bone mineral density in children and adolescent females treated with high doses of L-thyroxine. Hormone Research 199339 127-131.

11 Kooh SW, Brnjac L, Ehlrich RM, Qureshi R \& Krishnan S. Bone mass in children with congenital hypothyroidism treated with thyroxine since birth. Journal of Pediatric Endocrinology and Metabolism $1996959-62$.

12 Saggese G, Bertelloni S, Baroncelli GI, Costa S \& Ceccarelli C. Bone mineral denisty in adolescent females treated with L-thyroxine: a longitudinal study. European Journal of Pediatrics $1996 \mathbf{1 5 5}$ $452-457$.

13 Leger J, Ruiz JC, Guibourdence J, Kindermans C, Garabedian M \& Czernichow P. Bone mineral density and metabolism in children with congenital hypothyroidism after prolonged L-thyroxine therapy. Acta Paediatrica 199786 704-710.

14 Tumer L, Hasanoglu A, Cinaz P \& Bideci A. Bone mineral density and metabolism in children treated with L-thyroxine. Journal of Pediatric Endocrinology and Metabolism 199912 519-523.

15 Tanner JM, Whitehouse RH \& Takaishi M. Standards from birth to maturity for height, weight, height velocity and weight velocity: British children 1965. Archives of Disease in Childhood $1966 \mathbf{4 1}$ 613-635.

16 del Puente A, Postiglione A, Esposito-del Puente A, Carpinelli A, Romano M \& Oriente P. Peripheral body fat has a protective role on bone mineral density in elderly women. European Journal of Clinical Nutrition $1998 \mathbf{5 2}$ 690-693.

17 del Puente A, Heyse SP, Mandes MG, Mantova D, Carpinelli A, Nutile G \& Oriente P. Epidemiology of osteoporosis in women in southern Italy. Aging Clinical and Experimental Research 199810 $53-58$.

18 Baroncelli GI, Federico G, Bertelloni S, De Terlizzi F, Cadossi R \& Saggese G. Bone quality assessment by quantitative ultrasound of proximal phalanxes of the hand in healthy subjects aged 3-21 years. Pediatric Research $200149713-718$.

19 Consensus Conference, Osteoporosis prevention, diagnosis, and therapy. Journal of the American Medical Association 2001285 785-795.

20 Saggese G, Baroncelli GI \& Bertelloni S. Osteoporosis in children and adolescents: diagnosis, risk factor, and prevention. Journal of Pediatric Endocrinology and Metabolism 200114 833-849.

21 Greenspan SL \& Greenspan FS. The effect of thyroid hormone on skeletal integrity. Annals of Internal Medicine $1999130750-758$.

22 Singer PA, Cooper DS, Levy EG, Ladenson PW, Braverman LE, Daniels G et al. Treatment guidelines for patients with hyperthyroidism and hypothyroidism. Standards of Care Committee, American Thyroid Association. Journal of the American Medical Association $1995273808-812$.

23 Finkelstein JS, Neer RM, Biller BMK, Crawford JD \& Klibanski A. Osteopenia in men with a history of delayed puberty. New England Journal of Medicine $1992 \mathbf{3 2 6} 600-604$.

24 Bertelloni S, Baroncelli GI, Ferdeghini M, Perri G \& Saggese G. Normal volumetric bone mineral density and bone turnover in young men with histories of constitutional delay of puberty. Journal of Clinical Endocrinology and Metabolism $1998 \mathbf{8 3} 4280-4283$.

25 Matkovic V, Jelic T, Wardlaw GM, Ilich JZ, Goel PK, Wright JK, Andon MB, Smith KT \& Heaney RP. Timing of peak bone mass in Caucasian females and its implication for the prevention of osteoporosis. Inference from a cross-sectional model. Journal of Clinical Investigation 199493 799-808.

26 Lu PW, Briody JN, Ogle GD, Morley K, Humphries IR, Allen J, Howman-Giles R, Sillence D \& Cowell CT. Bone mineral density 
of total body, spine, and femoral neck in children and young adults: a cross-sectional and longitudinal study. Journal of Bone and Mineral Research $199491451-1458$.

27 Fournier PE, Rizzoli R, Slosman DO, Theintz G \& Bonjour JP. Asynchrony between the rates of standing height gain and bone mass accumulation during puberty. Osteoporosis International 19977 525-532.

28 Bonjour J, Theintz G, Buchs B, Slosman D \& Rizzoli R. Critical years and stages of puberty for spinal and femoral bone mass accumulation during adolescence. Journal of Clinical Endocrinology and Metabolism 199173 555-563.

29 Chan GM, Hoffman K \& MacMurry M. Effects of dairy products on bone and body composition in pubertal girls. Journal of Pediatrics $199512551-556$.

30 Bonjour JP, Carrie AL, Ferrari S, Clavien H, Slosman D, Theintz G \& Rizzoli R. Calcium-enriched foods and bone mass growth in prepubertal girls: a randomized, double-blind, placebo-controlled trial. Journal of Clinical Investigation 199799 1287-1294.

31 Njeh CF, Boivin CM \& Langton CM. The role of ultrasound in the assessment of osteoporosis: a review. Osteoporosis International $199777-22$

32 Baroncelli GI, Federico G, Bertelloni S, Sodini F, De Terlizzi F, Cado R \& Saggese G. Assessment of bone quality by quantitative ultrasound of proximal phalanges of the hand and fracture rate in children adolescents with bone and mineral disorders. Pediatric Research 200354 125-136.

Received 26 May 2004

Accepted 13 September 2004 